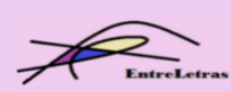

REVISTA ENTRELETRAS (ARAGUAÍNA), V. 12, N. 3, SET./DEZ. 2021 (ISSN 2179-3948 - ONLINE)

\title{
APRESENTAÇÃO DO DOSSIÊ: ARTE LITERÁRIA NA AMÉRICA LATINA COMO VIA DE DESCOLONIZAÇÃO
}

DOI 10.20873/uft2179-3948.2021v12n3p1-5

\section{María Rosa Lojo ${ }^{1}$ Marcela Crespo Buiturón ${ }^{2}$ Gilmei Francisco Fleck ${ }^{3}$}

Este dossiê temático foi pensado desde o espaço de pesquisa do Grupo "Ressignificações do passado na América: processos de leitura, escrita e tradução de gêneros híbridos de história e ficção - vias para a descolonização” da Universidade Estadual do Oeste do Paraná-UNIOESTE/Cascavel-PR/Brasil, que procura reunir estudos que evidenciam as distintas formas que a arte literária tem encontrado no espaço pós-colonial da América Latina para evidenciar a ainda manutenção de certas ações, empreendimentos e pensamentos colonialistas e as vias necessárias à descolonização. Isso, necessariamente, conduz-nos às formas como a arte literária tem ressignificado (criticamente) ou renarrativizado (acriticamente) o passado colonial de subjugação e exploração pelo qual as nações latino-americanas passaram ao longo de séculos.

A confrontação de discursos sobre o passado - sejam eles oriundos da história tradicional, da literatura acrítica ou crítica, da antropologia, da sociologia, etc. -, realizada por meio dos procedimentos da Literatura Comparada (GUILLÉN, 1985; COUTINHO, 2003; NITIRNI, 2000; FLECK; CERDEIRA; OLIVEIRA, 2020), que procurem evidenciar o fato de que "a superstição que afirma ser possível a verdade absoluta deu origem a opressivos sistemas políticos e religiosos, dos quais nunca conseguimos nos libertar: e jamais podemos fazê-lo enquanto aceitarmos a condição prévia que habilitou todos eles, isto é, a possibilidade de alguma verdade que seja absoluta" (CLARK; HOLQUIST, 1998, p. 363). Entre os gêneros híbridos de história que apresentam essa confrontação dos diferentes discursos sobre o passado, destacamos as diversas modalidades do romance histórico produzidos na atualidade (AÍNSA 1991; MENTON, 1993; ESTEVES, 2010; WEINHARDT, 2011; FLECK, 2017) o drama histórico (OLIVEIRA, 2020; TURKIEWICZ; OLIVEIRA, 2021), o poema histórico (LOPEZ,

\footnotetext{
${ }^{1}$ Docente da USAL - Buenos Aires.

2 Docente da USAL - Buenos Aires.

${ }^{3}$ Docente da UNIOESTE, Cascavel (Paraná).
} 


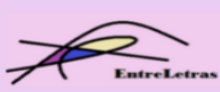

REVISTA ENTRELETRAS (ARAGUAÍNA), V. 12, N. 3, SET./DEZ. 2021 (ISSN 2179-3948 - ONLINE)

PÉREZ ANZOLA, 2020; 2021), os relatos de memória e de testemunho (ACHÚGAR, 2002; SILVA，2016; FIGUEIREDO，2018; FIGUEIREDO; SANTOS，2020) e, ainda，outras possibilidades que a arte literária explora para evidenciar a confluência de discursos sobre o passado em tessituras escriturais polissêmicas.

A partir dessa convocação, a presente edição da EntreLetras reuniu para a seção relativa ao dossiê vinte trabalhos, que versam sobre produções literárias diversas, tendo como eixo comum a reflexão sobre a decolonialidade. A seguir, fazemos uma breve apresentação dos textos que compõem o dossiê, de antemão agradecendo a todos que aceitaram nosso convite, enriquecendo um precioso e necessário debate. Agradecemos, ainda, aos muitos pareceristas que colaboraram com a edição.

Um olhar descolonizador interessa fundamentalmente ao trabalho crítico de tradução, sobretudo quanto estão em questão produções de autores latino-americanos e as opções de natureza ideológica que concorrem para a manutenção do que constitui a diferença e a alteridade ou seu apagamento. É dessa temática que tratam Keven de Almeida Antunes, Gilmei Francisco Fleck e Liliane Lemos Santana Barreiros em A tradução literária de obras latino-americanas: o processo de domesticação como apagamento da cultura do outro - novas colonizações, ao abordarem traduções de romances de Jorge Amado.

Também se dedicam à problemática da tradução, sob um olhar decolonial, as reflexões de Aline de Freitas Santos, Elaina Cristina dos Santos Costa e Patrício Nunes Barreiros: A (des)construção da cultura brasileira e sua ressignificação na tradução de Casa grande e senzala (1933) e Macunaíma (1978): vias para a decolonialidade na América Latina.

Mobilizando a teoria dos polissistemas, Jorge Antonio Berndt, Leila Shaí Del Pozo González e Phelipe de Lima Cerdeira analisam o trabalho de tradução em Xicoténcatl (1826) no polissitema latino-americano e a sua tradução: uma reflexão possível do entre-lugar e a desconstrução de Hernán Cortés.

Yetzabeth Pérez Anzola e Lorena Mujica González apresentam La “Alocución a la poesia" y la "Agricultura de la zona tórrida" como expresiones poéticas de una postura política cuestionada y "sospechosa" dentro del pensamiento americanista de Andrés Bello. Trata-se da análise da produção poética do venezuelano, escrita durante os anos de guerra pela independência. 


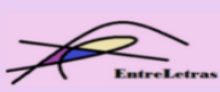

REVISTA ENTRELETRAS (ARAGUAÍNA), V. 12, N. 3, SET./DEZ. 2021 (ISSN 2179-3948 - ONLINE)

Mercedes Magdalena Rodríguez aborda o relato traumático relacionado ao movimento estudantil no México, em 1968, no artigo El enunciado de/sobre la violencia en La noche de Tlatelco, de Elena Poniatowska. Aqui entra em cena uma reflexão sobre a literatura de testemunho no contexto latino-americano.

Adenilson de Barros de Albuquerque traz sua contribuição para o dossiê com o artigo Canudos/Paraguai: regressos ficcionais das guerras, em que analisa os romances Canudos de Antônio Conselheiro, de Hélio de Araújo (2018), e Paraízo-Paraguay, de Marcelo Labes (2019), textos que convidam o leitor a revisitar dois fatos da história do país pelo viés literário.

Celeste Maria Pacheco de Andrade, Cristian Javier Lopez e Weslei Roberto Candido participam com o artigo História e literatura em diálogo: visões sobre o Romanceiro da inconfidência mineira (1953), de Cecília Meireles. Defendem os autores que o poema pode ser pensado sob uma mirada decolonial. Mediante uma escrita singular e subjetiva, desenvolvemse imagens que recriam o cenário histórico, as personagens históricas e as ações que culminaram em 1789.

Matilde Costa Fernandes de Souza, Simone Spiess e Luciene Souza Santos participam do dossiê com o artigo A leitura literária na escola: ressignificações do passado pela literatura híbrida infantil de história e ficção. Nele, as autoras retomam o conceito de hibridismo para discutir a relação entre literatura e história em textos destinados ao público infantil. No caso em questão, a "descoberta” das terras que seriam nomeadas Brasil, por Pedro Álvares Cabral, em 1500, é retomada pela recuperação de versões históricas trazidas pela Carta de Achamento do Brasil, de Pero Vaz de Caminha, na narrativa Barriga e Minhoca, Marinheiros de Cabral, de Atílio Bari (2002).

Fernanda Sacomori Candido Pedro, Douglas Rafael Facchinello e Margarida da Silveira Corsi seguem o olhar comparatista e interessado na perspectiva pedagógica em Liberdade ainda que tardia - a inserção da literatura juvenil como possibilidade de ressignificar o ensino de história: relações entre a obra A viagem proibida: nas trilhas do ouro (2013), de Mary Del Priore, e o livro didático História, sociedade \& cidadania (2018), de Alfredo Boulos Junior. Considerando a opção pela voz de personagens "ex-cêntricas" no relato histórico e tornadas protagonistas na literatura, os dois textos concorrem para o que se compreende como "romance histórico de mediação" (FLECK, 2017).

Outra escrita que analisa a relação entre literatura e história, na produção destinada a jovens leitores e sua contribuição de natureza didática, é Ressignificações do passado pela literatura híbrida juvenil: a assinatura da Lei Áurea: "libertação" dos escravos no Brasil - 


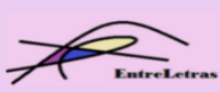

REVISTA ENTRELETRAS (ARAGUAÍNA), V. 12, N. 3, SET./DEZ. 2021 (ISSN 2179-3948 - ONLINE)

oficinas literárias, de Carla Cristiane Saldanha Fant, Márcio da Silva Oliveira e Rosângela Margarete Scopel da Silva.

Ainda considerando a perspectiva didática, temos Tumbu (2007): da liberdade na África à escravidão no Brasil - ressignificações do passado escravagista pela literatura híbrida juvenil e a formação do leitor consciente, de Marta Richciki Camargo, Raimundo Nonato Duarte Corrêa e Vilson Pruzak dos Santos.

O bilinguajamento como estratégia decolonial é tematizado por Nádia Nelziza Lovera de Florentino em Mar paraguayo: o experimentalismo nas fronteiras da descolonização, romance constituído nos limiares de prosa e poesia que dá destaque ao guarani, língua indígena posta em destaque.

Hugo Eliecer Dorado Mendez, Rosangela de Jesus Silva e Gilmei Francisco Fleck contribuem com Mi Simón Bolívar (1930): um novo paradigma literário. Para os autores, o romance de González Ochoa será precursor de uma nova modalidade do romance histórico latino-americano, ao antecipar características da modalidade crítica, pelo emprego de recursos como a paródia, a carnavalização, a intertextualidade e artifícios metanarrativos.

A figura histórica de Colombo é analisada por sua reconfiguração no romance de Stephen Marlowe em Colombo revisitado: de sujeito universal a sujeito fragmentado, de Luana Paiola e Valdeci Batista de Melo Oliveira.

O papel histórico feminino traduzido pela literatura é tematizado por Amanda Maria Elsner Matheus, Beatrice Uber e Marina Luísa Rodhe no artigo Mulheres: revisitações históricas sob o prisma ficcional - olhares que ressignificam. Segunda as autoras, o reconhecimento concedido a personagens mulheres no discurso ficcional concorre para descentralizar a "verdade histórica" edificada pela matriz positivista.

É ainda do papel feminino na história que trata o artigo Ressignificações de Anacaona na literatura infantojuvenil haitiana: Anacaona, Aytit's taino queen/Anacaona, la reine taino d'Aytiti (2012), de Maryse Noël Roumain - enfrentamentos com os escritos oficiais, de Carlos Henrique Lopes de Almeida, Michele de Fátima Sant'Ana e Tatiane Cristina Becher. Os autores analisam o romance no qual a cacica haitiana atua frente à exploração espanhola no período colonial da América hispânica.

Ana Maria Klock e Thiana Nunes Cella analisam romances que tratam do povoamento do norte do Paraná em Ressignificações do passado paraense em Terra vermelha ([1998] 2013), de Domingos Pellegrini: da história da terra à história do homem. 
Em A poesia de Herzer num exercício de decolonização dos corpos, Walace Rodrigues analisa trabalhos do poeta transsexual Anderson "Bigode" Herzer (1962-1982), nascido como Sandra Mara Herzer. Conforme Rodrigues, os poemas proporcionam reflexões em torno do gênero, da infância, dos cuidados e afetos.

Ana Maria Klock trata do enfrentamento ao pensamento eurocêntrico pela literatura em O romance histórico no contexto da nova narrativa latino-americana: veredas para a descolonização da história pela ficção.

Fecha o dossiê o artigo de Rosmere Adriana Vivian Ottonelli e Gilmei Francisco Fleck: O romance histórico contemporâneo de mediação Ana Néri, a brasileira que venceu a guerra (2002): a presença feminina na Guerra do Paraguai (1864-1870). 